JOURNAL OF SYNCHROTRON RADIATION

Received 18 December 2018

Accepted 13 May 2019

Edited by V. Favre-Nicolin, CEA and Université Joseph Fourier, France

Keywords: diamond; minerals; microinclusions; computed microtomography; microdiffraction; radiography.

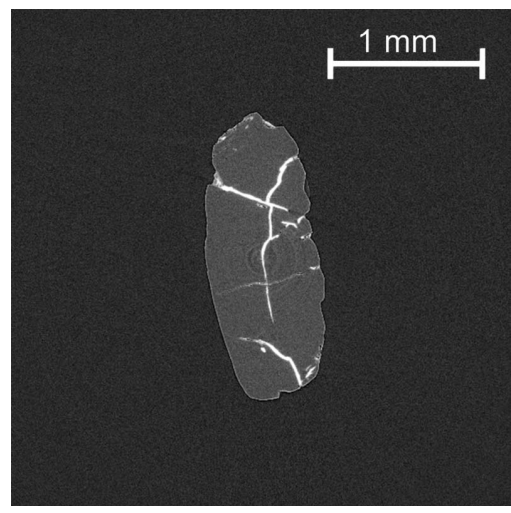

OPEN $\odot$ ACCESS

\section{Fast identification of mineral inclusions in diamond at GSECARS using synchrotron X-ray microtomography, radiography and diffraction}

\author{
Michelle D. Wenz, ${ }^{\text {a* }}$ Steven D. Jacobsen, ${ }^{a}$ Dongzhou Zhang,

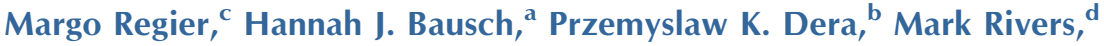 \\ Peter Eng, ${ }^{d}$ Steven B. Shirey ${ }^{\mathrm{e}}$ and D. Graham Pearson ${ }^{\mathrm{c}}$
}

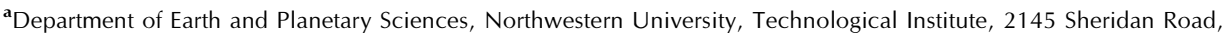
Evanston, IL 60208, USA, 'bawaii Institute of Geophysics and Planetology, University of Hawaii, Honolulu, HI 96822 , USA, 'Department of Earth and Atmospheric Sciences, University of Alberta, Edmonton, Alberta T6G 2E9, USA, ${ }^{\mathbf{d}}$ Center for Advanced Radiation Sources, The University of Chicago, Chicago, IL 60637, USA, and ${ }^{\mathbf{e}}$ Department of Terrestrial Magnetism, Carnegie Institution for Science, Washington DC 20015, USA. *Correspondence e-mail: michellewenz2020@u.northwestern.edu
\end{abstract}

Mineral inclusions in natural diamond are widely studied for the insight that they provide into the geochemistry and dynamics of the Earth's interior. A major challenge in achieving thorough yet high rates of analysis of mineral inclusions in diamond derives from the micrometre-scale of most inclusions, often requiring synchrotron radiation sources for diffraction. Centering microinclusions for diffraction with a highly focused synchrotron beam cannot be achieved optically because of the very high index of refraction of diamond. A fast, high-throughput method for identification of micromineral inclusions in diamond has been developed at the GeoSoilEnviro Center for Advanced Radiation Sources (GSECARS), Advanced Photon Source, Argonne National Laboratory, USA. Diamonds and their inclusions are imaged using synchrotron 3D computed X-ray microtomography on beamline 13-BM-D of GSECARS. The location of every inclusion is then pinpointed onto the coordinate system of the six-circle goniometer of the single-crystal diffractometer on beamline 13BM-C. Because the bending magnet branch 13-BM is divided and delivered into 13-BM-C and 13-BM-D stations simultaneously, numerous diamonds can be examined during coordinated runs. The fast, high-throughput capability of the methodology is demonstrated by collecting 3D diffraction data on 53 diamond inclusions from Juína, Brazil, within a total of about $72 \mathrm{~h}$ of beam time.

\section{Introduction}

Most diamonds are thought to crystalize in the mantle roots of the continental lithosphere (Stachel \& Harris, 2008), whereas so-called super-deep diamonds and their inclusions are believed to crystalize in the convecting upper mantle, transition zone and even lower mantle (Nestola et al., 2018; Palot et al., 2016; Pearson et al., 2014, 2003; Shirey et al., 2013; Stachel et al., 2005). Provided that the host diamonds are not cracked, minerals included within them are essentially encapsulated in an inert preservation vessel during eruption to the surface in kimberlitic magmas. The study of these micromineral inclusions provides insight into the geochemistry and dynamics of the Earth's crust-mantle system from otherwise unattainable depths (Harte, 2011; Pearson et al., 2014; Smith et al., 2018). In the past, the study of diamond inclusions has been largely limited to destructive techniques, such as breaking the diamond to release inclusions or grinding away the host diamond to expose inclusions at the surface. In addition, the use of laboratory-source X-rays limits the minimum size of 
inclusion that can be identified by X-ray diffraction. Destructive extraction techniques have the inherent risk of losing or altering the inclusions, which are usually under remnant pressure inside the diamond host (Angel et al., 2015). Thus, by studying these encapsulated inclusions using nondestructive methods, properties such as inclusion pressure, oxidation state, high-pressure phases and volatile content remain preserved.

To date, in situ identification of mineral inclusions in diamond via non-destructive methods remains challenging as the very high refractive index of diamond $(n \simeq 2.4)$ hinders typical identification methods, such as optical microscopy or Raman spectroscopy, unless the inclusion is very close to a flat diamond surface. The high $n$ of diamond also makes optical centering methods for single-crystal diffraction time consuming (Kunz et al., 2002; Nestola et al., 2012). In 2011, the first in situ crystal structure refinement of an inclusion in diamond was performed on an olivine crystal measuring $\sim 80 \mu \mathrm{m}$ in the largest dimension using a sealed-tube Mo $K \alpha$ source (Nestola et al., 2011). In that study, two large and parallel faces of the diamond facilitated optical centering of the inclusion. Subsequently, synchrotron radiation has been employed to carry out in situ structure refinements of clinopyroxenes entrapped in diamond (Nestola et al., 2016). Centering microinclusions inside highly irregular diamonds with an X-ray beam for diffraction can be accomplished by combining tomography with X-ray diffraction. Recently, this combined approach was employed by Nestola et al. (2012) using laboratory sources in Padova, Italy. The use of a laboratory source is ideal for the study of large $(>50 \mu \mathrm{m})$ inclusions, but a method to quickly identify the multitude of smaller inclusions in large available suites of super-deep diamonds is required to obtain a more thorough sampling of inclusion mineralogy.

In this paper, we describe a fast, high-throughput and nondestructive methodology for identifying microinclusions in diamond as small as $10-20 \mu \mathrm{m}$ in the maximum dimension by combining synchrotron microtomography with a newly developed radiography system now installed on the singlecrystal diffraction beamline of the GeoSoilEnviro Center for Advanced Radiation Sources (GSECARS), Advanced Photon Source (APS), USA. Such a fast yet thorough method allows for all inclusions within the full volume of each diamond to be identified, thus allowing for a better relative modal proportion of inclusions to be obtained as smaller inclusions, which would be missed if only utilizing optical methods are not overlooked. In addition, the use of microtomography prior to diffraction provides detailed information on the integrity of the diamond host, revealing microcracks that may indicate the potential for metasomatic alteration of the inclusions. By identifying all microinclusions within a suite of super-deep diamonds, more information about the environment wherein superdeep diamonds form is obtained. The efficiency of the system is demonstrated by collecting 3D diffraction data from 53 inclusions in a total of 23 different diamonds from Juína, Brazil, all within a total of about $72 \mathrm{~h}$ of beam time. This result is unachievable by any other method.

\section{Experimental}

\subsection{Synchrotron microtomography}

Synchrotron microtomography, used to physically locate mineral inclusions within the diamond, was conducted at GSECARS, beamline 13-BM-D, of the APS. The configuration of the 13-BM branch allows for simultaneous delivery of the X-ray beam to both 13-BM-D (microtomography) and 13BM-C (single-crystal X-ray diffraction) beamlines. Thus, during coordinated runs the diamonds go directly from 13BM-D to the newly developed 2D radiography and singlecrystal diffraction system at 13-BM-C, which hosts the Partnership for eXtreme Xtallography $\left(\mathrm{PX}^{\wedge} 2\right)$, a collaboration between the University of Hawaii and GSECARS, supported by the Consortium for Materials Properties Research in Earth Sciences (COMPRES). This facility is funded by COMPRES to advance crystallographic studies of minerals and materials under conditions of extreme pressures, temperatures and strain rates. A schematic diagram of the microtomography beamline illustrates the configuration used for super-deep diamonds, many of which have irregular shapes (Fig. 1). A monochromatic beam with an energy of $28.9 \mathrm{keV}$ was chosen for this approach as this energy closely matches the operating energy of the 13-BM-C (28.6 keV) diffraction beamline. Due to the diffraction of the scintillator itself, Ce-doped LuAG, the exact operation energy of 13-BM-C could not be used because artifacts appeared in the tomographic reconstructions. Choosing a similar operating energy guarantees that all inclusions visible at the 13-BM-D beamline will also appear in the $2 \mathrm{D}$ radiography system at $13-\mathrm{BM}-\mathrm{C}$. Due to the variability in both size and shape of super-deep diamonds, an adjustable field of view (FOV) is required to accurately map all inclusions. A typical FOV for large diamonds $(\sim 6 \mathrm{~mm})$ is around $8.70 \mathrm{~mm}$ by $5.44 \mathrm{~mm}$. Collection times are on the order of 15 min per diamond, thus within a $24 \mathrm{~h}$ time period, full tomography on the entire volume of over 90 diamonds is achievable.

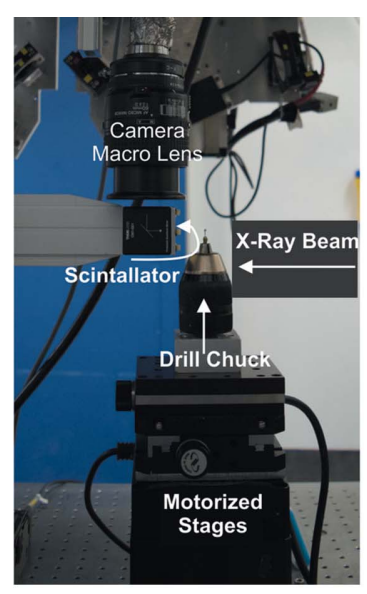

(a)

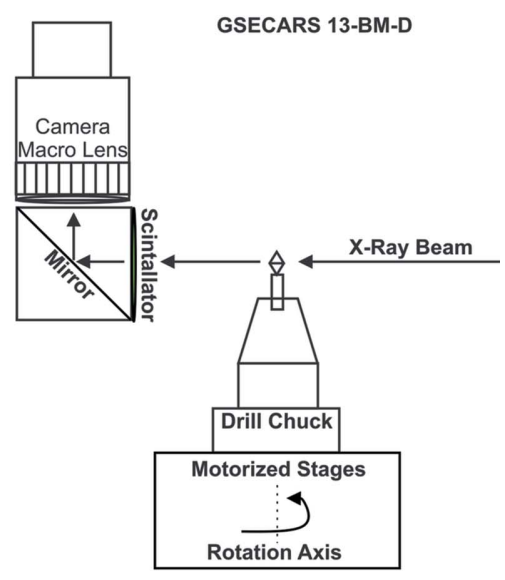

(b)
Figure 1

(a) Photograph and (b) schematic of the microtomography setup at 13BM-D, GSECARS, Advanced Photon Source. 


\subsection{Synchrotron X-ray diffraction}

Single-crystal X-ray diffraction measurements were carried out at GSECARS, beamline 13-BM-C, of the APS. Combining microtomography and X-ray diffraction required the development of a portable $2 \mathrm{D}$ radiography attachment at 13-BM-C for the centering procedure. The components of this live radiography system consist of a scintillator, mirror, a $5 \times$ objective and a GigE camera. All components are mounted onto a motorized stage, which enables the radiography system to drive in and out of the X-ray beam (Fig. 2). Thus, the 2D radiography setup does not interfere with the six-circle goniometer during diffraction collection. EPICS areaDetector (Rivers, 2018; Rivers et al., 2010) and ImageJ (Schneider et al., 2012) are used to view the live radiograph while allowing for the constant normalization to a flat-field image.

The first step in setting up the diffraction experiment is to identify the rotation axis of the diffractometer and intersect the X-ray beam with it. The rotation axis of the diffractometer is set up in the horizontal direction, perpendicular to the incident X-ray (Zhang et al., 2017). A focused X-ray beam with a full width at half-maximum of $12 \mu \mathrm{m}(\mathrm{H}) \times 18 \mu \mathrm{m}(\mathrm{V})$ is achieved by horizontal and vertical Kirkpatrick-Baez mirrors (Eng et al., 1998). The rotation axis of the diffractometer is visualized by rotating a $25 \mu \mathrm{m}$-diameter tungsten wire. Once the tungsten wire ceases to precess during rotation, the tungsten wire coincides with the rotation axis. The X-ray beam vertical position is then adjusted until maximum absorption is detected. At this stage, the X-ray beam intersects the rotation axis of the diffractometer and the tungsten wire is then removed. The incident beam position is marked on the scintillator image with a virtual crosshair, which corresponds to the intersection of the rotation axis and the X-ray.

Obtaining a live radiograph image of the inclusion on the 13-BM-C diffraction beamline requires defocusing the $\mathrm{X}$-ray beam to increase the FOV. An FOV of $\sim 100 \mu \mathrm{m}(\mathrm{H}) \times 250 \mu \mathrm{m}$ (V) is achieved by defocusing the Kirkpatrick-Baez mirrors, giving a magnified image of the inclusion for centering. Each inclusion is located by observing its absorption shadow in the radiograph image. Locating inclusions in this magnified FOV requires the use of high-resolution ( $4.5 \mathrm{~mm}$ per pixel) microtomography data obtained at beamline 13-BM-D prior to diffraction. Without microtomography data the process can take an hour or more to locate an inclusion within such a magnified FOV, whereas with the microtomography map it takes only a few minutes. Once an inclusion is found within the FOV and placed into the virtual crosshair, a rotation centering of the inclusion is performed in $5^{\circ}$ steps, thus centering the inclusion on the rotation axis. Once the inclusion is properly centered, the X-ray beam then is refocused back to the virtual crosshair and the scintillator is driven out of the beam path. Single-crystal X-ray diffraction using a six-circle goniometer proceeds following standard X-ray diffraction protocols (Zhang et al., 2017). It takes $5 \mathrm{~min}$ to collect a wide-scan diffraction image (rotation of $180^{\circ}$ ), and $30 \mathrm{~min}$ for step scan collections (steps in scan $=180$, exposure time per degree $=1 \mathrm{~s}$, rotation of $180^{\circ}$ ) using the MAR $165 \mathrm{CCD}$ detector. The new Pilatus $1 \mathrm{M}$ detector with a $1 \mathrm{~mm}$ silicon sensor implemented in 2019 will speed these collections times up to a few minutes. Thus, 13-BM-C allows for fast diffraction analysis on a multitude of inclusions.

\section{Results}

To demonstrate the capabilities of this new fast, highthroughput combined synchrotron microtomography and X-ray diffraction technique, a suite of 61 diamonds from Juína, Brazil, were studied. Microtomography data were collected on all 61 diamonds using a CMOS camera with $1920 \times 1200$ pixels, $4.5 \mu \mathrm{m}$ pixel size on the sample, $1 \mathrm{~s}$ exposure time and 900 projections. All microtomography data on the 61 diamonds were collected within a $24 \mathrm{~h}$ period.

$\mathrm{X}$-ray diffraction data, obtained using the newly developed live 2D radiograph centering technique at 13-BM-C, were collected on 53 inclusions found within 23 of these super-deep

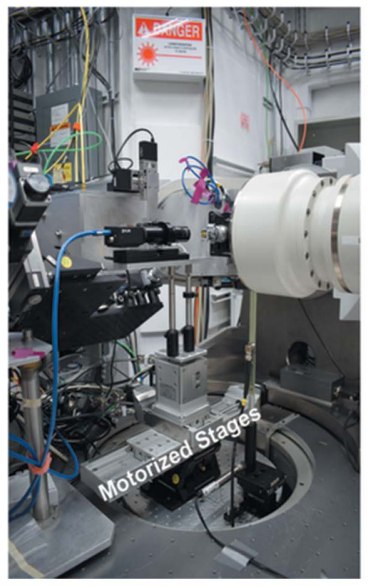

(a)

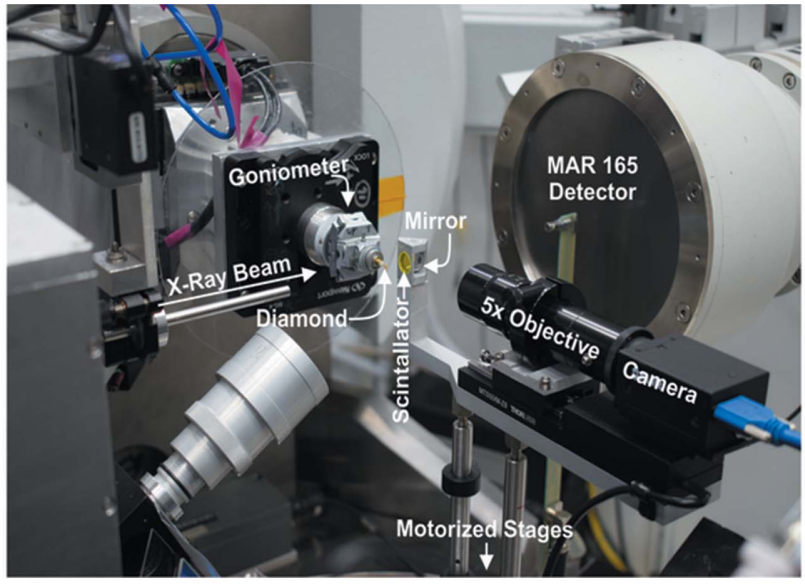

(b)

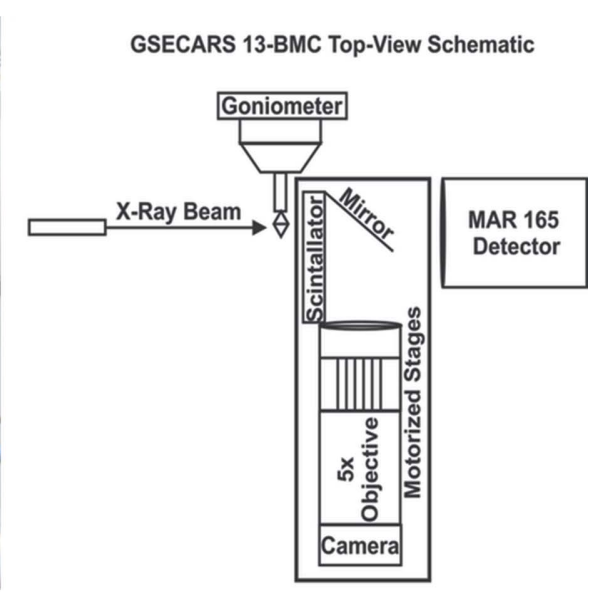

(c)

Figure 2

(a) Photograph of the entire portable radiograph attachment. (b) Close-up photograph of the portable radiography system. (c) Top-view schematic of the portable radiography system at 13-BM-C. The rectangle represents the motorized stage, yet also highlights the main components that make up the newly developed portable 2D radiography system available at 13-BM-C. 
Table 1

Symmetry-constrained lattice parameters of 53 inclusions identified in a suite of diamonds from the São Luiz locality in Juína, Brazil. Single-crystal inclusions denoted by *, the rest of the inclusions are powder.

\begin{tabular}{|c|c|c|c|c|c|c|c|c|c|}
\hline Inclusion & $a(\AA)$ & $b(\AA)$ & $c(\AA)$ & $\alpha\left(^{\circ}\right)$ & $\beta\left({ }^{\circ}\right)$ & $\gamma\left({ }^{\circ}\right)$ & $\begin{array}{l}\text { Volume } \\
\left(\AA^{3}\right)\end{array}$ & $\begin{array}{l}\text { Symmetry } \\
\text { constraints }\end{array}$ & Mineral \\
\hline 6b_04b* & $8.509(2)$ & $8.509(2)$ & $8.509(2)$ & 90 & 90 & 90 & $616.0(2)$ & Cubic & Titanomagnetite $\mathrm{Fe}_{1+x}\left(\mathrm{Fe}_{2-2 x} \mathrm{Ti}_{x}\right) \mathrm{O}_{4}$ \\
\hline $6 b \_04 b 2 *$ & $4.255(1)$ & $4.255(1)$ & $4.255(1)$ & 90 & 90 & 90 & $77.1(6)$ & Cubic & Ferropericlase $\left(\mathrm{Mg}_{x}, \mathrm{Fe}_{1-x}\right) \mathrm{O}$ \\
\hline 6b_05a* & $4.246(4)$ & $4.246(4)$ & $4.246(4)$ & 90 & 90 & 90 & $76.6(2)$ & Cubic & Ferropericlase $\left(\mathrm{Mg}_{x}, \mathrm{Fe}_{1-x}\right) \mathrm{O}$ \\
\hline 6b_05b* & $4.255(2)$ & $4.255(2)$ & $4.255(2)$ & 90 & 90 & 90 & $77.0(2)$ & Cubic & Ferropericlase $\left(\mathrm{Mg}_{x}, \mathrm{Fe}_{1-x}\right) \mathrm{O}$ \\
\hline 6b_05c* & $4.259(1)$ & $4.259(1)$ & $4.259(1)$ & 90 & 90 & 90 & $77.3(1)$ & Cubic & Magnesiowüstite $\left(\mathrm{Mg}_{1-x}, \mathrm{Fe}_{x}\right) \mathrm{O}$ \\
\hline 6b_05d* & $4.262(2)$ & $4.262(2)$ & $4.262(2)$ & 90 & 90 & 90 & $77.4(2)$ & Cubic & Magnesiowüstite $\left(\mathrm{Mg}_{1-x}, \mathrm{Fe}_{x}\right) \mathrm{O}$ \\
\hline 6b_05e* & $4.251(2)$ & $4.251(2)$ & $4.251(2)$ & 90 & 90 & 90 & $77.4(2)$ & Cubic & Ferropericlase $\left(\mathrm{Mg}_{x}, \mathrm{Fe}_{1-x}\right) \mathrm{O}$ \\
\hline 6b_06a* & $4.276(2)$ & $4.276(2)$ & $4.276(2)$ & 90 & 90 & 90 & $78.2(1)$ & Cubic & Magnesiowüstite $\left(\mathrm{Mg}_{1-x}, \mathrm{Fe}_{x}\right) \mathrm{O}$ \\
\hline 6b_06b* & $4.271(7)$ & $4.271(7)$ & $4.271(7)$ & 90 & 90 & 90 & $77.9(1)$ & Cubic & Magnesiowüstite $\left(\mathrm{Mg}_{1-x}, \mathrm{Fe}_{x}\right) \mathrm{O}$ \\
\hline 6b_07a & $2.868(9)$ & $2.868(9)$ & $2.868(9)$ & 90 & 90 & 90 & $23.6(2)$ & Cubic & Fe (b.c.c.) with some alloy \\
\hline 6b_07b & $2.868(5)$ & $2.868(5)$ & $2.868(5)$ & 90 & 90 & 90 & $23.6(1)$ & Cubic & Fe (b.c.c.) with some alloy \\
\hline 6b_07c* & $4.276(2)$ & $4.276(2)$ & $4.276(2)$ & 90 & 90 & 90 & $78.2(1)$ & Cubic & Magnesiowüstite $\left(\mathrm{Mg}_{1-x}, \mathrm{Fe}_{x}\right) \mathrm{O}$ \\
\hline 6b_07c2* & $8.442(5)$ & $8.442(5)$ & $8.442(5)$ & 90 & 90 & 90 & $601.7(3)$ & Cubic & Titanomagnetite $\mathrm{Fe}_{1+x}\left(\mathrm{Fe}_{2-2 x} \mathrm{Ti}_{x}\right) \mathrm{O}_{4}$ \\
\hline 6b_07d* & $4.204(5)$ & $4.204(5)$ & $4.204(5)$ & 90 & 90 & 90 & $75.3(3)$ & Cubic & Ferropericlase $\left(\mathrm{Mg}_{x}, \mathrm{Fe}_{1-x}\right) \mathrm{O}$ \\
\hline $6 b \_07 d 2 *$ & $8.511(1)$ & $8.511(1)$ & $8.511(1)$ & 90 & 90 & 90 & $601.7(3)$ & Cubic & Titanomagnetite $\mathrm{Fe}_{1+x}\left(\mathrm{Fe}_{2-2 x} \mathrm{Ti}_{x}\right) \mathrm{O}_{4}$ \\
\hline $6 b \_07 e^{*}$ & $4.320(7)$ & $4.320(7)$ & $4.320(7)$ & 90 & 90 & 90 & $81.0(4)$ & Cubic & Wüstite $\mathrm{FeO}$ \\
\hline $6 \mathrm{~b} \_07 \mathrm{e} 2 *$ & $8.490(5)$ & $8.490(5)$ & $8.490(5)$ & 90 & 90 & 90 & $612.0(2)$ & Cubic & Titanomagnetite $\mathrm{Fe}_{1+x}\left(\mathrm{Fe}_{2-2 x} \mathrm{Ti}_{x}\right) \mathrm{O}_{4}$ \\
\hline 6b_08c* & $5.083(1)$ & $5.083(1)$ & $5.083(1)$ & 90 & 90 & 120 & $314.6(3)$ & Hexagonal & Ilmenite $\mathrm{FeTiO}_{3}$ \\
\hline 6b_09 & $4.640(6)$ & $10.005(9)$ & $3.028(3)$ & 90 & 90 & 90 & $140.6(2)$ & Orthorhombic & Goethite (FeOOH) \\
\hline 6b_10b & $5.032(1)$ & $5.032(1)$ & $13.759(3)$ & 90 & 90 & 120 & $301.7(1)$ & Hexagonal & Hematite $\mathrm{Fe}_{2} \mathrm{O}_{3}$ \\
\hline $6 \mathrm{~b} \_10 \mathrm{c}$ & $5.140(3)$ & $5.140(3)$ & $13.420(2)$ & 90 & 90 & 120 & $307.5(2)$ & Hexagonal & Titanohematite $\left[x \mathrm{FeTiO}_{3}(1-x) \mathrm{Fe}_{2} \mathrm{O}_{3}\right]$ \\
\hline $6 b \_11 b *$ & $8.396(2)$ & $8.396(2)$ & $8.396(2)$ & 90 & 90 & 90 & $591.8(2)$ & Cubic & Magnetite $\mathrm{Fe}_{3} \mathrm{O}_{4}$ \\
\hline $6 b \_12 a *$ & $4.273(2)$ & $4.273(2)$ & $4.273(2)$ & 90 & 90 & 90 & $78.0(3)$ & Cubic & Magnesiowüstite $\left(\mathrm{Mg}_{1-x}, \mathrm{Fe}_{x}\right) \mathrm{O}$ \\
\hline $6 b \_12 b *$ & $4.270(1)$ & $4.270(1)$ & $4.270(1)$ & 90 & 90 & 90 & $77.9(2)$ & Cubic & Magnesiowüstite $\left(\mathrm{Mg}_{1-x}, \mathrm{Fe}_{x}\right) \mathrm{O}$ \\
\hline $6 b \_12 c *$ & $4.280(9)$ & $4.280(9)$ & $4.280(9)$ & 90 & 90 & 90 & $78.4(5)$ & Cubic & Magnesiowüstite $\left(\mathrm{Mg}_{1-x}, \mathrm{Fe}_{x}\right) \mathrm{O}$ \\
\hline $6 b \_12 d^{*}$ & $4.274(3)$ & $4.274(3)$ & $4.274(3)$ & 90 & 90 & 90 & $78.1(5)$ & Cubic & Magnesiowüstite $\left(\mathrm{Mg}_{1-x}, \mathrm{Fe}_{x}\right) \mathrm{O}$ \\
\hline $6 b \_17 b^{*}$ & $4.270(1)$ & $4.270(1)$ & $4.270(1)$ & 90 & 90 & 90 & $77.8(2)$ & Cubic & Magnesiowüstite $\left(\mathrm{Mg}_{1-x}, \mathrm{Fe}_{x}\right) \mathrm{O}$ \\
\hline $6 b \_17 c^{*}$ & $4.285(1)$ & $4.285(1)$ & $4.285(1)$ & 90 & 90 & 90 & $78.7(5)$ & Cubic & Magnesiowüstite $\left(\mathrm{Mg}_{1-x}, \mathrm{Fe}_{x}\right) \mathrm{O}$ \\
\hline $6 b \_21 c^{*}$ & $4.279(2)$ & $4.279(2)$ & $4.279(2)$ & 90 & 90 & 90 & $78.3(2)$ & Cubic & Magnesiowüstite $\left(\mathrm{Mg}_{1-x}, \mathrm{Fe}_{x}\right) \mathrm{O}$ \\
\hline $6 b \_21 c 2$ & $8.405(2)$ & $8.405(2)$ & $8.405(2)$ & 90 & 90 & 90 & $593.8(2)$ & Cubic & Titanomagnetite $\mathrm{Fe}_{1+x}\left(\mathrm{Fe}_{2-2 x} \mathrm{Ti}_{x}\right) \mathrm{O}_{4}$ \\
\hline $6 b \_23 *$ & $4.232(8)$ & $4.232(8)$ & $4.232(8)$ & 90 & 90 & 90 & $75.8(3)$ & Cubic & Ferropericlase $\left(\mathrm{Mg}_{x}, \mathrm{Fe}_{1-x}\right) \mathrm{O}$ \\
\hline 6b_29a* & $4.261(2)$ & $4.261(2)$ & $4.261(2)$ & 90 & 90 & 90 & $77.8(2)$ & Cubic & Magnesiowüstite $\left(\mathrm{Mg}_{1-x}, \mathrm{Fe}_{x}\right) \mathrm{O}$ \\
\hline 6b_29b* & $4.253(1)$ & $4.253(1)$ & $4.253(1)$ & 90 & 90 & 90 & $76.9(1)$ & Cubic & Ferropericlase $\left(\mathrm{Mg}_{x}, \mathrm{Fe}_{1-x}\right) \mathrm{O}$ \\
\hline $6 b \_34 a *$ & $4.243(2)$ & $4.243(2)$ & $4.243(2)$ & 90 & 90 & 90 & $76.4(2)$ & Cubic & Ferropericlase $\left(\mathrm{Mg}_{x}, \mathrm{Fe}_{1-x}\right) \mathrm{O}$ \\
\hline $6 b \_34 b *$ & $4.245(1)$ & $4.245(1)$ & $4.245(1)$ & 90 & 90 & 90 & $76.5(1)$ & Cubic & Ferropericlase $\left(\mathrm{Mg}_{x}, \mathrm{Fe}_{1-x}\right) \mathrm{O}$ \\
\hline $6 b \_34 c^{*}$ & $4.252(2)$ & $4.252(2)$ & $4.252(2)$ & 90 & 90 & 90 & $76.8(2)$ & Cubic & Ferropericlase $\left(\mathrm{Mg}_{x}, \mathrm{Fe}_{1-x}\right) \mathrm{O}$ \\
\hline $6 b \_37 a$ & $4.254(2)$ & $4.254(2)$ & $4.254(2)$ & 90 & 90 & 90 & $77.0(2)$ & Cubic & Ferropericlase $\left(\mathrm{Mg}_{x}, \mathrm{Fe}_{1-x}\right) \mathrm{O}$ \\
\hline $6 b \_37 a 2$ & $8.379(2)$ & $8.379(2)$ & $8.379(2)$ & 90 & 90 & 90 & $588.0(4)$ & Cubic & Magnetite $\mathrm{Fe}_{3} \mathrm{O}_{4}$ \\
\hline $6 \mathrm{~b} \_39 \mathrm{a}$ & $5.037(5)$ & $5.037(5)$ & $13.769(1)$ & 90 & 90 & 120 & $302.5(4)$ & Hexagonal & Titanohematite $\left[x \mathrm{FeTiO}_{3}(1-x) \mathrm{Fe}_{2} \mathrm{O}_{3}\right]$ \\
\hline $6 b \_39 b$ & $5.038(7)$ & $5.038(7)$ & $13.761(1)$ & 90 & 90 & 120 & $302.5(5)$ & Hexagonal & Titanohematite $\left[x \mathrm{FeTiO}_{3}(1-x) \mathrm{Fe}_{2} \mathrm{O}_{3}\right]$ \\
\hline $6 b \_46^{*}$ & $11.584(3)$ & $11.584(3)$ & $11.584(3)$ & 90 & 90 & 90 & $1554.4(6)$ & Cubic & Almandine $\mathrm{Fe}_{3} \mathrm{Al}_{2}\left(\mathrm{SiO}_{4}\right)_{3}$ \\
\hline $6 b \_48 b$ & $4.744(4)$ & $10.185(1)$ & $5.978(7)$ & 90 & 90 & 90 & $288.8(6)$ & Orthorhombic & Olivine $\left(\mathrm{Mg}_{x}, \mathrm{Fe}_{2-x}\right) \mathrm{SiO}_{4}$ \\
\hline $6 \mathrm{~b} \_53 *$ & $4.246(1)$ & $4.246(1)$ & $4.246(1)$ & 90 & 90 & 90 & $76.5(1)$ & Cubic & Ferropericlase $\left(\mathrm{Mg}_{x}, \mathrm{Fe}_{1-x}\right) \mathrm{O}$ \\
\hline $6 b \_54 b *$ & $6.609(2)$ & $6.609(2)$ & $6.001(3)$ & 90 & 90 & 90 & $262.1(2)$ & Tetragonal & Zircon $\mathrm{ZrSiO}_{4}$ \\
\hline $6 b \_56 a$ & $4.758(7)$ & $10.209(6)$ & $5.972(7)$ & 90 & 90 & 90 & $290.1(4)$ & Orthorhombic & Olivine $\left(\mathrm{Mg}_{x}, \mathrm{Fe}_{2-x}\right) \mathrm{SiO}_{4}$ \\
\hline $6 b \_56 b$ & $4.759(8)$ & $10.209(8)$ & $5.976(1)$ & 90 & 90 & 90 & $290.4(5)$ & Orthorhombic & Olivine $\left(\mathrm{Mg}_{x}, \mathrm{Fe}_{2-x}\right) \mathrm{SiO}_{4}$ \\
\hline 6b_56b2 & $8.394(6)$ & $8.394(6)$ & $8.394(6)$ & 90 & 90 & 90 & $591.4(1)$ & Cubic & Magnetite $\mathrm{Fe}_{3} \mathrm{O}_{4}$ \\
\hline $6 \mathrm{~b} \_56 \mathrm{c}$ & $4.754(1)$ & $10.205(7)$ & $5.978(1)$ & 90 & 90 & 90 & $290.0(6)$ & Orthorhombic & Olivine $\left(\mathrm{Mg}_{x}, \mathrm{Fe}_{2-x}\right) \mathrm{SiO}_{4}$ \\
\hline $6 \mathrm{~b} \_56 \mathrm{~d}$ & $4.756(1)$ & $10.206(1)$ & $5.981(1)$ & 90 & 90 & 90 & $290.3(6)$ & Orthorhombic & Olivine $\left(\mathrm{Mg}_{x}, \mathrm{Fe}_{2-x}\right) \mathrm{SiO}_{4}$ \\
\hline 5a_09a & $5.077(3)$ & $5.077(3)$ & $13.894(4)$ & 90 & 90 & 120 & $310.1(2)$ & Hexagonal & Titanohematite $\left[x \mathrm{FeTiO}_{3}(1-x) \mathrm{Fe}_{2} \mathrm{O}_{3}\right]$ \\
\hline 5a_09b & $5.069(2)$ & $5.069(2)$ & $13.931(5)$ & 90 & 90 & 120 & $310.1(2)$ & Hexagonal & Titanohematite $\left[x \mathrm{FeTiO}_{3}(1-x) \mathrm{Fe}_{2} \mathrm{O}_{3}\right]$ \\
\hline $5 \mathrm{a} \_10 \mathrm{f} *$ & $4.281(8)$ & $4.281(8)$ & $4.281(8)$ & 90 & 90 & 90 & $78.5(4)$ & Cubic & Magnesiowüstite $\left(\mathrm{Mg}_{1-x}, \mathrm{Fe}_{x}\right) \mathrm{O}$ \\
\hline $5 a \_20 c^{*}$ & $4.245(9)$ & $4.245(9)$ & $4.245(9)$ & 90 & 90 & 90 & $76.47(7)$ & Cubic & Ferropericlase $\left(\mathrm{Mg}_{x}, \mathrm{Fe}_{1-x}\right) \mathrm{O}$ \\
\hline
\end{tabular}

diamonds within a $72 \mathrm{~h}$ period. Sample-to-detector distances and tilt were calibrated using diffraction of $\mathrm{LaB}_{6}$. Singlecrystal inclusion diffraction data were processed using the program ATREX (previously GSE_ADA; Dera et al., 2013), which handles peak searching and fitting routines allowing for the generation of a peak list. To index the peaks, the peak list generated in ATREX was read into the program Reciprocal Space Viewer (Dera et al., 2013), where peak indexing, orientation matrix determination and refinement of lattice parameters were performed. For powder inclusions as well as mixed-phase inclusions (inclusions with both powder and single-crystal phases), diffraction images were first integrated in DIOPTAS (Prescher \& Prakapenka, 2015), a program designed specifically for handling large amounts of data collected at XRD beamlines in order to generate intensity versus $2 \theta$ plots. These $2 \theta$ plots were then imported into the program GSAS-II (Toby \& Von Dreele, 2013) for further lattice parameter processing, indexing and refinement. Inclusions were ultimately identified via their lattice parameters.

Lattice parameters for the 53 inclusions are shown in Table 1. A summary of all minerals found from these diamonds is given in Table 2. The majority of inclusion phases 
Table 2

Summary of all minerals found in the 23 diamonds from the São Luiz locality in Juína, Brazil.

\begin{tabular}{ll}
\hline Mineral & No. of inclusions \\
\hline Ferropericlase $\left(\mathrm{Mg}_{x}, \mathrm{Fe}_{1-x}\right) \mathrm{O}$ & 13 \\
Magnesiowüstite $\left(\mathrm{Mg}_{1-x}, \mathrm{Fe}_{x}\right) \mathrm{O}$ & 14 \\
Wüstite $\mathrm{FeO}$ & 1 \\
Magnetite $\left(\mathrm{Fe}_{3} \mathrm{O}_{4}\right)$ & 3 \\
Titanomagnetite $\mathrm{Fe}_{1+x}\left(\mathrm{Fe}_{2-2 x} \mathrm{Ti}_{x}\right) \mathrm{O}_{4}$ & 5 \\
Hematite $\left(\mathrm{Fe}_{2} \mathrm{O}_{3}\right)$ & 1 \\
Titanohematite $\left[x \mathrm{FeTiO}_{3}(1-x) \mathrm{Fe}_{2} \mathrm{O}_{3}\right]$ & 5 \\
Olivine $\left(\mathrm{Mg}_{x}, \mathrm{Fe}_{2-x}\right) \mathrm{SiO}_{4}$ & 5 \\
Iron $(\mathrm{Fe})$ & 2 \\
Goethite $\left(\mathrm{FeOOH}_{4} \mathrm{FeO}_{\text {Imenite }\left(\mathrm{FeTiO}_{3}\right)}\right.$ & 1 \\
Garnet $\mathrm{Fe}_{3} \mathrm{Al}_{2}\left(\mathrm{SiO}_{4}\right)_{3}$ & 1 \\
Zircon $\left(\mathrm{ZrSiO}_{4}\right)$ & 1 \\
\hline
\end{tabular}

form solid solutions. Thus, unit-cell volumes are dependent on both composition and remnant pressure. Phases along the hematite $\left(\mathrm{Fe}_{2} \mathrm{O}_{3}\right)$ to ilmenite $(\mathrm{FeTiO} 3)$ solid solution are referred to as titanohematite (Brown et al., 1993). Phases along the magnetite $\left(\mathrm{Fe}_{3} \mathrm{O}_{4}\right)$ to ulvöspinel $\left(\mathrm{Fe}_{2} \mathrm{TiO}_{4}\right)$ solid solution are referred to as titanomagnetite (Bosi et al., 2009). Olivine phases refer to those along the forsterite $\left(\mathrm{Mg}_{2} \mathrm{SiO}_{4}\right)$ to fayalite $\left(\mathrm{Fe}_{2} \mathrm{SiO}_{4}\right)$ solid solution series. Following standard mineralogical nomenclature, the $(\mathrm{Mg}, \mathrm{Fe}) \mathrm{O}$ oxides are classified such that samples containing $<50 \mathrm{~mol} \% \mathrm{FeO}$ are referred to as ferropericlase and those with $>50 \mathrm{~mol} \%$ are magnesiowüstite (Jacobsen et al., 2002; Prewitt \& Downs, 1998). We note however that there is large uncertainty in the composition of such inclusions studied in situ using lattice parameters alone. For $(\mathrm{Mg}, \mathrm{Fe}) \mathrm{O}$, assuming the variation of lattice parameter with $X_{\mathrm{Fe}}=\Sigma \mathrm{Fe} /(\Sigma \mathrm{Fe}+\mathrm{Mg})$ and an average bulk modulus $K_{\mathrm{T} 0}$ of $160 \mathrm{GPa}$ from the work of Jacobsen et al. (2002), the value of $X_{\mathrm{Fe}}$ would be underestimated by about 0.088 (or $8.8 \mathrm{~mol} \% \mathrm{FeO}$ ) per GPa of remnant pressure.

It is interesting to note that the majority of the inclusions identified in our study are ferropericlase $(\mathrm{Mg}, \mathrm{Fe}) \mathrm{O}$. Ferropericlase was reported previously as a predominate mineral in Juína diamonds and has often been associated with signifying a lower mantle origin (Anzolini et al., 2019; Kaminsky et al., 2009), whereas more non-pyrolitic Fe-rich ( $\mathrm{Mg}, \mathrm{Fe}) \mathrm{O}$ inclusions are associated with conditions of diamond growth (Nimis et al., 2019). Thomson et al. (2016)

proposed that the presence of $(\mathrm{Mg}, \mathrm{Fe}) \mathrm{O}$ inclusions may be related to the reactions between the carbonatitic melt and reduced mantle peridotite. The range of intermediate and Fe-rich compositions reported in ferropericlase inclusions in diamond may represent different stages of the reaction (Thomson et al., 2016). Because the numerous ferropericlase inclusions in the current suite of Juína diamonds are not associated with any high-pressure mineral inclusions, they are possibly associated with the melt

Figure 3 reactions proposed by Thomson et al. (2016) and Nimis et al. (2019).

The advantages of high-resolution microtomography extend beyond the X-ray centering procedure as this technique also reveals information on both the number and quality of the inclusions. Super-deep diamonds exhibit rough irregular shapes as well as different surface textures, which often preclude optical observation. Tomography reveals all inclusions, even those not visible under optical microscopes, and also provides a way of checking that the inclusion is pristine. Super-deep diamonds experience extreme stresses and therefore some exhibit microcracks only visible via tomography [Fig. 3(a)]. These cracks often lead up to or surround an inclusion, which indicates that an inclusion may have interacted with kimberlitic magma or has cracked as a result of a difference in the elastic relaxation between the inclusion and the host diamond. Such information is lost when inclusions are extracted and yet this information is important when considering how representative an inclusion is of the mantle.

The capability to pre-screen inclusions also exists with microtomography. The reconstructed slices, i.e. maps of the absorption, provide the ability to distinguish between high and low X-ray absorbing inclusions. Differences in absorption indicate compositional differences owing to the mean atomic weight differences. Inclusions with high iron contents such as ferropericlase, $(\mathrm{Mg}, \mathrm{Fe}) \mathrm{O}$, appear brighter in the tomographic slice than inclusions with lower absorbing material such as silicates or graphite [Figs. 3(b) and 3(c)].

\section{Conclusions}

A fast, high-throughput method developed at GSECARS (Sector 13) of the APS provides the opportunity for dozens of inclusions within a diamond suite to be identified within days (Fig. 4). The high quality of both the microtomography and $\mathrm{X}$-ray data reveals clues to the history of the inclusion. Identifying all inclusions within a diamond suite garners insight into the composition and geochemical cycling of Earth's dynamic mantle that remains unattainable with small sample sets. Serving as the only samples from such depths, diamond inclusions hold the key to unlocking the secrets of Earth's mantle.

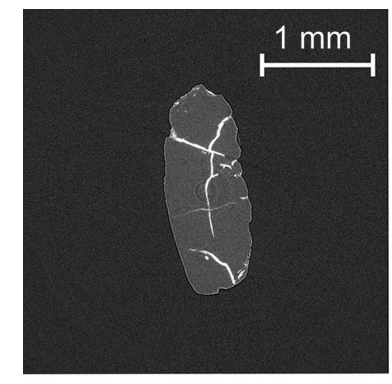

(a)

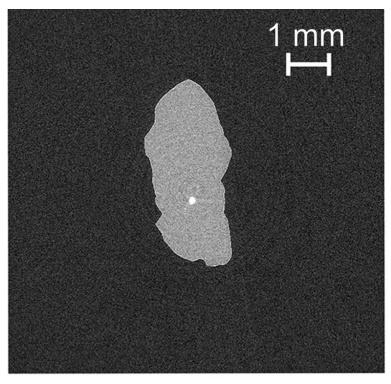

(b)

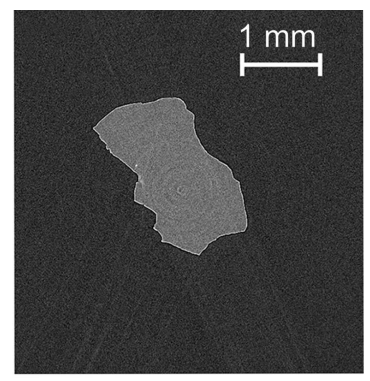

(c)

(a) Tomographic slice of diamond 6b_24 exhibiting multiple cracks. (b) Tomographic slice of diamond 6b_09 with a high-absorbing goethite inclusion, FeOOH. (c) Tomographic slice of diamond 6b_56 with a less absorbing silicate inclusion olivine, $(\mathrm{Mg}, \mathrm{Fe})_{2} \mathrm{SiO}_{4}$. 


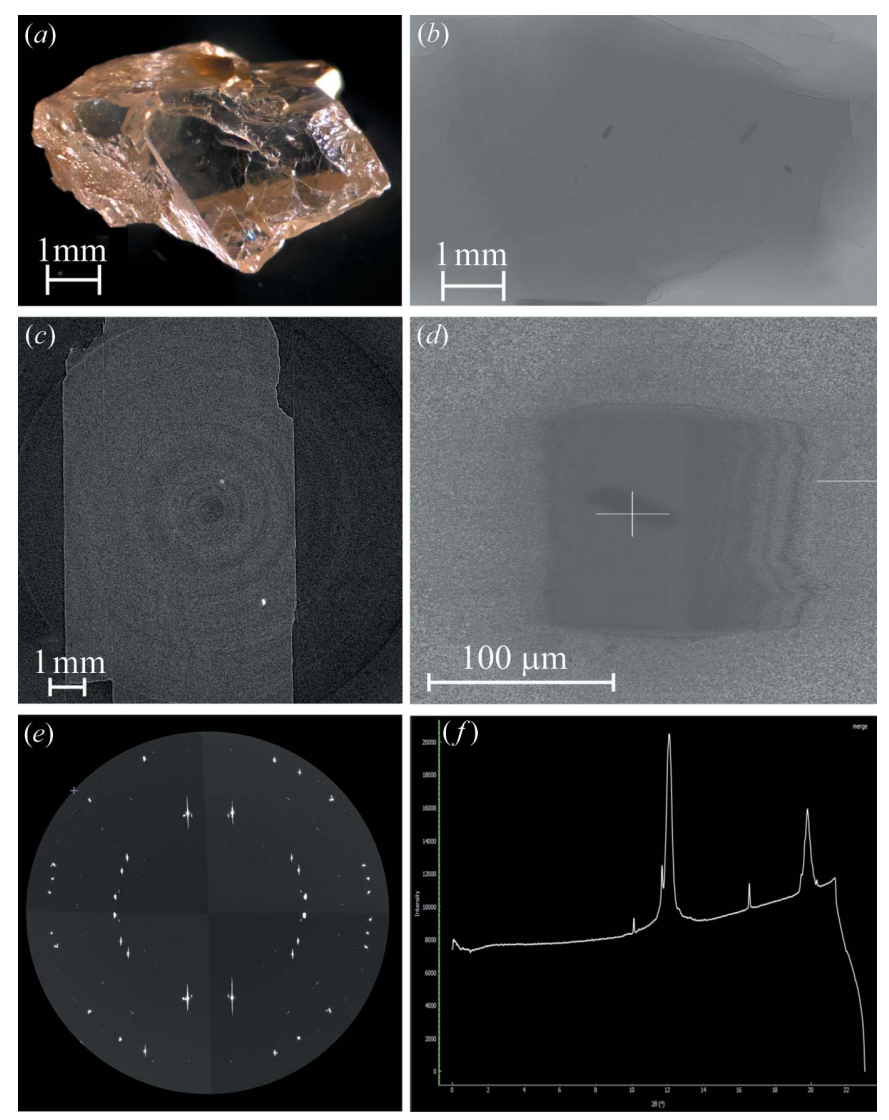

Figure 4

(a) Photomicrograph of Juína diamond 6B_06. (b) Radiograph of diamond 6B_06 taken at 13-BM-D. (c) Reconstructed slice of diamond 6B_06 from 13-BM-D data. Rings observed in the image are artifacts. (d) Radiograph of one of the ferropericlase inclusions in $(b)$ taken at 13BM-C. (e) Wide-scan $\left(180^{\circ}\right.$ rotation) XRD image of a ferropericlase inclusion in diamond 6B_06 shown in $(d)$. $(f)$ Integrated diffraction pattern of ferropericlase inclusion in diamond 6b_06, image produced using DIOPTAS (Prescher \& Prakapenka, 2015).

\section{Funding information}

This study was supported in part through the US National Science Foundation (NSF) (grant No. EAR-1853521 to SDJ) and by the Capital/DOE Alliance Center (CDAC). DGP and SBS acknowledge support from the Deep Carbon Observatory (Sloan Foundation). This work was performed at GeoSoilEnviroCARS (GSECARS), The University of Chicago, at Sector 13 of the APS, Argonne National Laboratory. GSECARS is supported by the NSF (grant No. EAR-1634415) and US Department of Energy (DOE) (grant No. DE-FG02-94ER14466). Experiments at beamline 13-BM$\mathrm{C}$ used the $\mathrm{PX}^{\wedge} 2$ facility, supported by COMPRES under NSF Cooperative Agreement (EAR-1661511). The APS is supported by the DOE and operated for the DOE Office of Science by Argonne National Laboratory (contract No. DEAC02-06CH11357).

\section{References}

Angel, R. J., Alvaro, M., Nestola, F. \& Mazzucchelli, M. L. (2015). Russ. Geol. Geophys. 56, 225-234.
Anzolini, C., Nestola, F., Mazzucchelli, M. L., Alvaro, M., Nimis, P., Gianese, A., Morganti, S., Marone, F., Campione, M., Hutchison, M. \& Harris, J. W. (2019). Geology, 47, 219-222.

Bosi, F., Halenius, U. \& Skogby, H. (2009). Am. Mineral. 94, 181189.

Brown, N. E., Navrotsky, A., Nord, G. L. Jr \& Banerjee, S. K. (1993). Am. Mineral. 78, 941-951.

Dera, P., Zhuravlev, K., Prakapenka, V., Rivers, M. L., Finkelstein, G. J., Grubor-Urosevic, O., Tschauner, O., Clark, S. \& Downs, R. T. (2013). High. Press. Res. 33, 465-484.

Eng, P. J., Newville, M., Rivers, M. L. \& Sutton, S. R. (1998). Proc. SPIE, 3449, 145-156.

Harte, B. (2011). Science, 334, 51-52.

Jacobsen, S. D., Reichmann, H. J., Spetzler, H. A., Mackwell, S. J., Smyth, J. R., Angel, R. J. \& McCammon, C. A. (2002). J. Geophys. Res. 107, 1-14.

Kaminsky, F., Khachatryan, G. K., Andreazza, P., Araujo, D. \& Griffin, W. L. (2009). Lithos, 112, 833-842.

Kunz, M., Gillet, P., Fiquet, G., Sautter, V., Graafsma, H., Conrad, P. \& Harris, J. (2002). Earth Planet. Sci. Lett. 198, 485-493.

Nestola, F., Alvaro, M., Casati, M. N., Wilhelm, H., Kleppe, A. K., Jephcoat, A. P., Domeneghetti, M. C. \& Harris, J. W. (2016). Lithos, 265, 334-338.

Nestola, F., Korolev, N., Kopylova, M., Rotiroti, N., Pearson, D. G., Pamato, M. G., Alvaro, M., Peruzzo, L., Gurney, J. J., Moore, A. E. \& Davidson, J. (2018). Nature, 555, 237-241.

Nestola, F., Merli, M., Nimis, P., Parisatto, M., Kopylova, M., Stefano, A., Longo, M., Ziberna, L. \& Manghnani, M. (2012). Eur. J. Mineral. 24, 599-606.

Nestola, F., Nimis, P., Ziberna, L., Longo, M., Marzoli, A., Harris, J. W., Manghnani, M. H. \& Fedortchouk, Y. (2011). Earth Planet. Sci. Lett. 305, 249-255.

Nimis, P., Nestola, F., Schiazza, M., Reali, R., Agrosì, G., Mele, D., Tempesta, G., Howell, D., Hutchison, M. T. \& Spiess, R. (2019). Geology, 47, 27-30.

Palot, M., Jacobsen, S. D., Townsend, J. P., Nestola, F., Marquardt, K., Miyajima, N., Harris, J. W., Stachel, T., McCammon, C. A. \& Pearson, D. G. (2016). Lithos, 265, 1-7.

Pearson, D. G., Brenker, F. E., Nestola, F., McNeill, J., Nasdala, L., Hutchison, M. T., Matveev, S., Mather, K., Silversmit, G., Schmitz, S., Vekemans, B. \& Vincze, L. (2014). Nature, 507, 221-224.

Pearson, D. G., Canil, D. \& Shirey, S. B. (2003). Treatise on Geochemistry, 1st ed., pp. 171-275. Amsterdam: Elsevier Science.

Prescher, C. \& Prakapenka, V. B. (2015). High. Press. Res. 35, $223-$ 230.

Prewitt, C. T. \& Downs, R. T. (1998). Rev. Mineral. Geochem. 37, $283-$ 317.

Rivers, M. (2017). Proceedings of the 16th International Conference on Accelerator and Large Experimental Control Systems (ICALEPCS2017), 8-13 October 2017. Barcelona, Spain, pp. 1245-1251, Geneva, Switzerland. THDPL03.

Rivers, M., Garrett, R., Gentle, I., Nugent, K. \& Wilkins, S. (2010). AIP Conf. Proc. 1234, 51-54.

Schneider, C. A., Rasband, W. S. \& Eliceiri, K. W. (2012). Nat. Methods, 9, 671-675.

Shirey, S. B., Cartigny, P., Frost, D. J., Keshav, S., Nestola, F., Pearson, G. D., Sobolev, N. V. \& Walter, M. J. (2013). Rev. Mineral. Geochem. 75, 355-421.

Smith, E. M., Shirey, S. B., Richardson, S. H., Nestola, F., Bullock, E. S., Wang, J. \& Wang, W. (2018). Nature, 560, 84-87.

Stachel, T., Brey, P. \& Harris, J. W. (2005). Elements, 1, 73-78.

Stachel, T. \& Harris, J. W. (2008). Ore Geol. Rev. 34, 5-32.

Thomson, A. R., Walter, M. J., Kohn, S. C. \& Brooker, R. A. (2016). Nature, 529, 76-79.

Toby, B. H. \& Von Dreele, R. B. (2013). J. Appl. Cryst. 46, 544549.

Zhang, D., Dera, P., Eng, P. J., Stubbs, J. E., Zhang, J. S., Prakapenka, V. B. \& Rivers, M. L. (2017). J. Vis. Exp. 119, e54660. 